\title{
The environmental control of urban planning in the Syrian desert cities
}

\author{
Muhammad Mahdy Alsous ${ }^{1,2, *}$ \\ ${ }^{1}$ Damascus University, Faculty of Architecture, Aljamarek St., 2040, Damascus, Syria \\ ${ }^{2}$ Moscow State University of Civil Engineering, Yaroslavskoye Shosse, 26, Moscow, 129337, Russia
}

\begin{abstract}
Analysis the changes on the city's image of the traditional desert communities and the principles of urban planning in their cities as a result of technical and environmental changes which achieved in the modern era. It was concluded, that It was necessary to research and emphasize the concept of urban sustainability in overcoming the development problems in these cities by maximizing and activating the role of desert cities, revealing their development potentials and the best way to exploit them. It was concluded defining planning principles for desert cities adapted to the harsh environment, by examining the impact of the environmental content on the planning concepts of the Syrian desert cities (Palmyra city as an example), defining principles and criteria for environmental control in the planning of these cities and evaluating the existing planning of the traditional communities in the Syrian desert and the degree of its interaction with the surrounding environment.
\end{abstract}

\section{Introduction}

The development of desert cities in the twenty-first century was influenced by modern western directions and trends in urban planning [1]. As a result, the city's traditional desert image changed. Also, after the industrial revolution a new modern methods and techniques were introduced in the construction and transportation processes, which led to neglecting inherited techniques in the planning of traditional desert areas [2]. As a result, modern unsustainable cities with an economic system and a new industrial nature have formed on the urban areas.

Environmental planning is one of the approaches to dealing with the development of desert communities and the basis for the formulation of sustainable development strategies through the concepts of self-sufficiency and local autonomy [3].

The shape of the city may help in ventilation, wind speed and control of solar radiation within the city. The use of trees within the urban spaces in the areas of severe drought also reduces the temperature. Therefore, it was necessary to study the form of urbanization in the traditional desert communities through analytical studies of city morphology, transport network, planning principles, as an ancient city of Palmyra, as an attempt to prove the effectiveness of traditional planning components. These communities have learned over the centuries how to deal with their surrounding environment and solutions to housing and other

\footnotetext{
*Corresponding author: muh,alsous@gmail.com
} 
problems. The important objective of the current study was to analyze and evaluate the planning of traditional communities to determine the principles and criteria for how to control the future planning of the Syrian desert communities.

Until now, the urban planning studies in Syria have not highlighted the specificity of the desert areas planning and the need to benefit from the vast areas in the Syrian desert, which contain a lot of development potentials. Also, their role in the development process not only in the desert region but also its reflection on the development of the rest of the Syrian regions.

\section{Methods}

During the study of the urban planning of the desert's cities in Syria the authors had used literary sources, regulatory documents, project materials. The author used comparative analysis of the sources, on-site assessment of the objects as research methods.

\section{Analysis}

Badia al-Sham or the Syrian desert $[4,5]$ is located in the southeast of the Syrian Arab Republic and includes East Jordan, western Iraq and northern Saudi Arabia. It covers an area of 518,000 square kilometers (Fig. 1). The southern section is called the middle "Hammad" which lies between Arar and Jouf in northern Saudi Arabia.

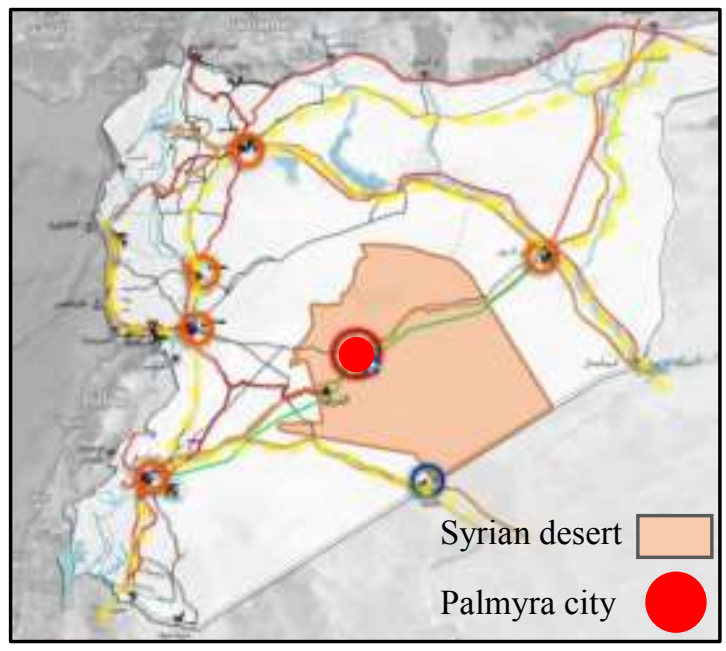

Fig. 1. Syrian desert [author's source].

The climate of the desert areas is characterized by high temperatures in the summer, where the maximum temperature of the shade rises to $45^{\circ}$ and may reach $50^{\circ}$. The lower end at night does not fall below $20^{\circ}[6]$.

The harsh climate was the result of the lack of clouds, the lack of vegetation and the high intensity of solar radiation, as well as the decrease in the amount and humidity of the air, where the relative humidity ranges from $20 \%$ in the afternoon to more than $40 \%$ at night. The rains are rare, And unstable.

Rain is characterized by low annual rainfall of only $127 \mathrm{~mm}$ [6]. Winds are hot with dust and often lead to sandstorms, which are the most important features of the hot desert climate. As we know, the environment affects cities due to the varied climatic conditions in the desert, man created the planning patterns that suit the desert environment. 


\subsection{Analysis the urban planning characteristics in the city of Palmyra}

The city of Palmyra is one of the most important cities in the Syrian desert and the urban center of this region (fig.2). After studying the characteristics of its urban planning, we can summarize it in the following points:

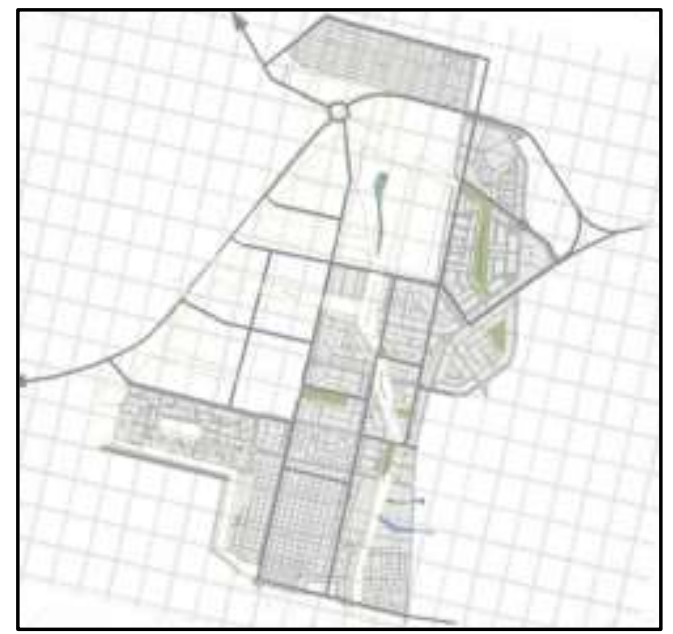

Fig. 2. Palmyra city plan [author's source].

\subsubsection{In terms of compatibility and compatibility with the desert environment and} climate

Our cities do not achieve compatibility and harmony with the desert environment [7]. Houses are exposed to dust storms and extreme external lightness, due to large areas exposed to solar radiation. Also, the urban spaces and streets are exposed and not shaded, which limits mobility, especially in daylight hours (Fig. 3).

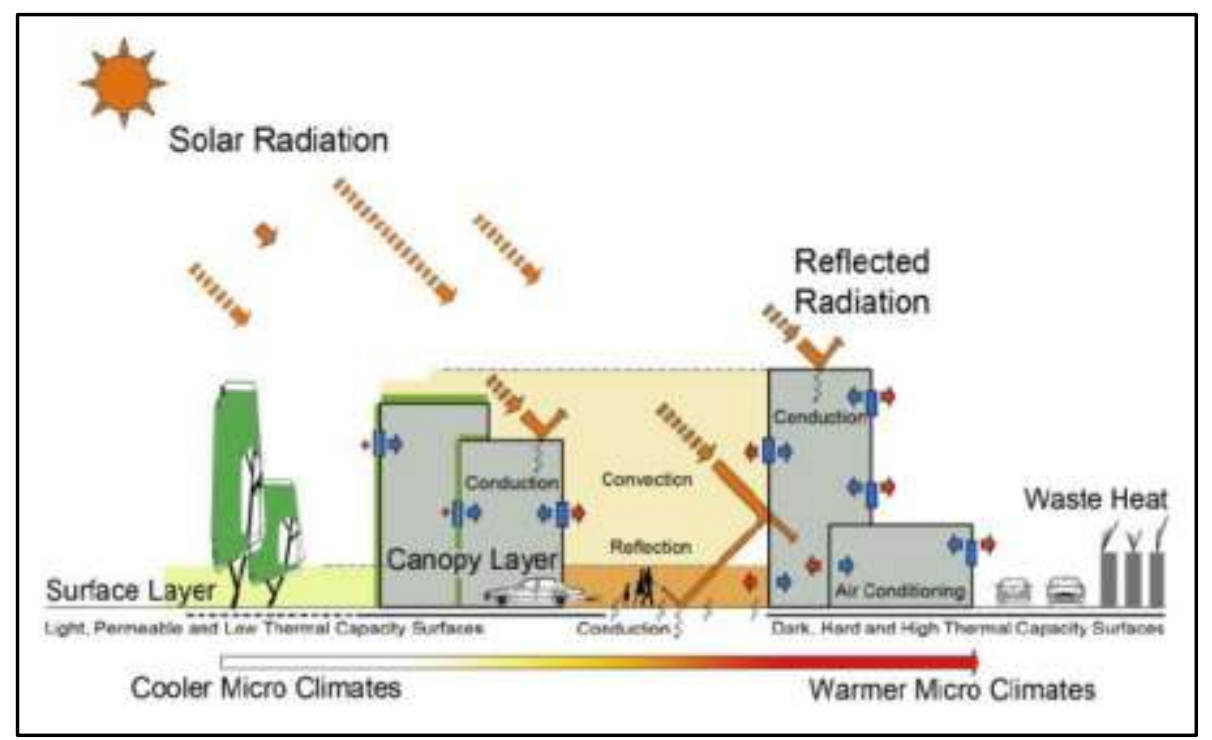

Fig. 3. Solar radiation and urban climate [author's source]. 


\subsubsection{In terms of privacy}

The privacy required is not achieved due to the lack of rules regulating the way and places of external openings, and the distance between buildings. To achieve privacy residents resort to not open windows and rely on artificial lighting and ventilation to achieve the required visual privacy.

\subsubsection{Street network planning}

The network of parallel streets with open ends [8] led to a long-distance network and thus increased traffic within one street, which increase the noise rate.

\subsubsection{In terms of security}

Safety is not achieved due to the absence of semi-functional spaces in which children can play, and the absence of safe pedestrian corridors as a result of their interference with the movement of cars.

\subsubsection{Economic aspects}

The current pattern of urban planning increases the demand for energy due to the exposure of most of the facades and buildings surfaces to the sun throughout the day, which increases the consumption of air conditioners and electricity, as well as rely on the car mainly for mobility, whatever the distance.

As a result, this pattern lost its human appearance, because the housing units diverged from each other to make room for the car. The ratio between building heights and road widths has been reduced, reducing the shading of pedestrian lanes.

\section{Results}

Through the previous analysis of the urban planning of the Syrian deserts, we find that there are fundamental considerations must be taken in account when developing the cities, the most important is its integration with the surrounding environment from natural and social terms, in addition to other principles can be summarized by the following points.

\subsection{Compact urban fabric patterns}

There is no doubt that the continuity and stability of the urban structure in the historical heart of the Arab cities for hundreds of years [9] has achieved the concept of social and functional communication for successive generations and form the distinctive sustainable urban identity (Fig. 4).

The closeness of buildings to each other, the narrow paths of movement between them and abundance of its curves led to protect the facades of the sun and the movement of hot winds within the spaces.

Due to the harshness of the desert environment, urban planning played a major role in containing the activities of the population, in addition to providing shadows and creating social spaces [10]. The integrated planning led to increased social relations among the population and formed smaller, simpler, less polluting and more sustainable communities. 


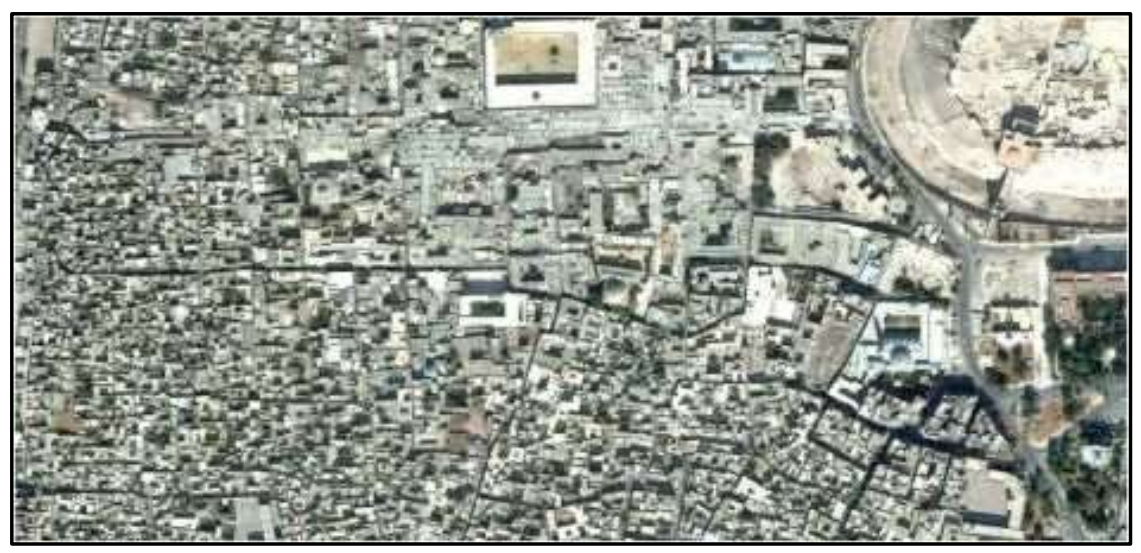

Fig. 4. Compact urban fabric - Aleppo, Syria [google earth].

\subsection{Directing the general plan of the Syrian desert cities}

The orientation of the urban fabric of the desert communities plays an important role in reducing the hot climate, by receiving and directing the favorable wind inside the urban block to provide ventilation inside the residential units and in the urban spaces [11].

It is known that the direction of the desired wind in the desert of Syria is the north and north-west [6], so the larger dimension of the buildings and spaces should be directed towards this direction to take advantage of the maximum amount of wind. Considering that this direction receives a relatively large amount of direct solar radiation. So, the best direction for city is to make the longitudinal axis of the buildings as east-west axis, so that the most facades are northern orientation far from solar radiation or with southern orientation facades which can be treated architecturally against solar radiation (Fig. 5).

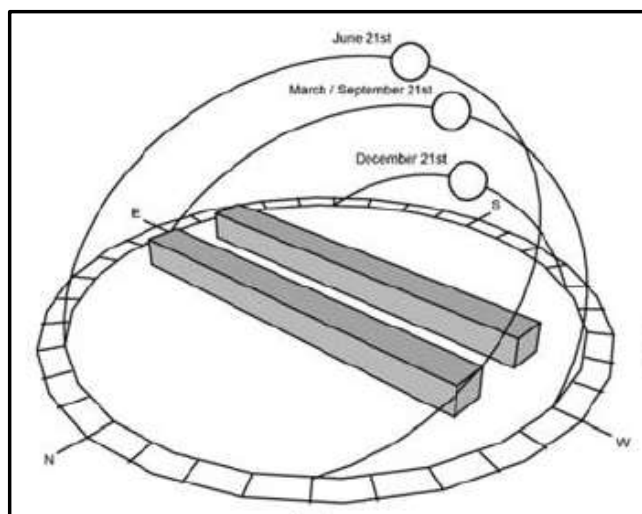

(a)

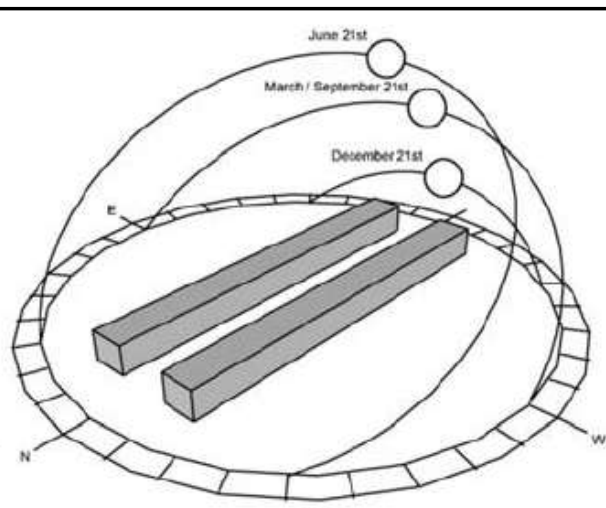

(b)

Fig. 5. The orientation of the urban fabric, (a) the best direction of the buildings, (b) un desirable orientation of the buildings [author's source].

\subsection{Traffic networks planning}

Decreasing the percentage of street area in the desert urban assembly to the lowest possible rate has an important effect on reducing the amount of solar radiation leakage and the stabilization of temperature within the mass of the urban assembly [12]. 
Also, the shape and the orientation of the transport network plays an important role in responding to the desert climate. The orthogonal grid design increases the movement of air within the urban mass and receives a large amount of solar radiation, while the narrow, curving design receives the least amount of direct solar radiation and is less exposed of wind loaded with sand. in addition, it increases the speed of air within the urban block and provide a suitable local atmosphere.

The coefficient of height of buildings to the width of the streets and its relation to the angle of sun in the street, should help to prevent sunlight to reach to the depth of the street and keep the shade of pedestrians during most of the day (Fig. 6).

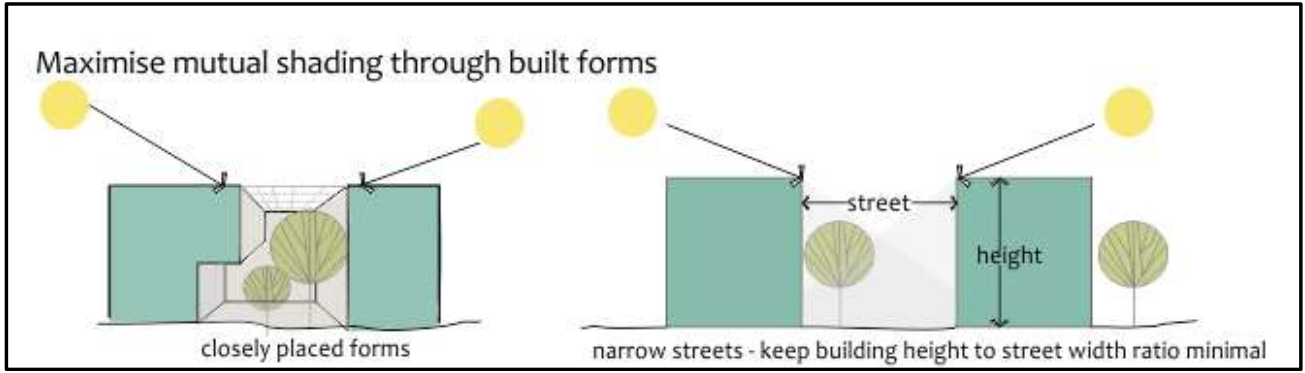

Fig. 6. The coefficient of height of buildings to the width of the streets and its relation to the angle of sun in the street [author's source].

The depth of the appropriate street in hot humid desert's weather communities is different from those in hot dry desert communities [13].

In the hot dry desert, the goal is to reach a stable climate, which requires increasing the depth of the streets. And in the hot humid desert, it is preferable to increase the shading with reducing the heights of the buildings, so the wet stagnant air can be moved from the bottom.

The proportionality between the width of the streets to their lengths helps to turn them into air distribution channels (Fig.7), so it is preferred to shorten the streets in dry desert areas and increase their lengths in the hot humid desert areas.

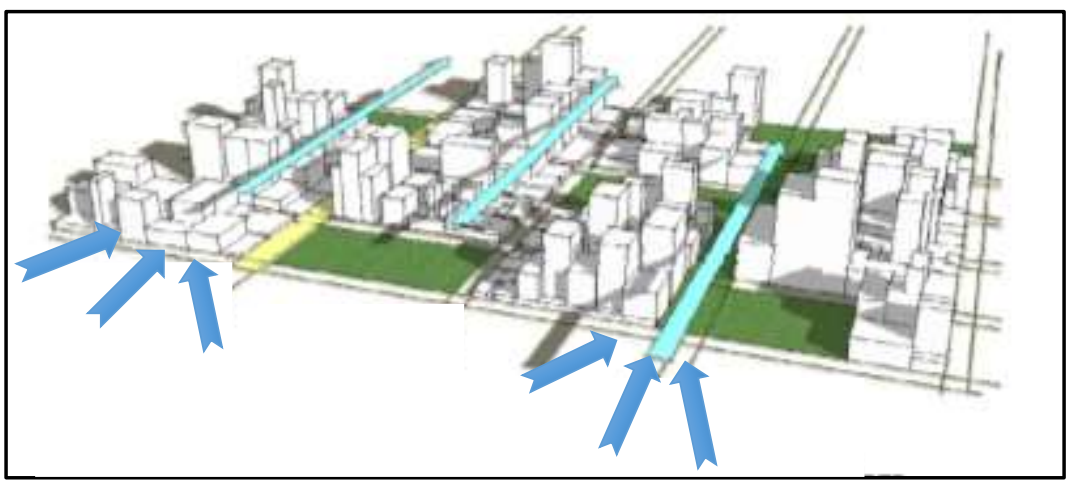

Fig. 7. Streets as air distribution channels [author's source].

\subsection{Climate control through the landscape in desert cities}

When planning and developing urban communities in desert areas, great importance is given to the landscape's elements in the sites. which play an important role in differing or reducing radiation as:

- The plant absorbs $75 \%$ of the solar radiation falling on it [14]; 
- Availability of thermal comfort at the bottom of the plant due to moisture generation;

- Control air movement;

- Control the removal or addition of moisture.

\section{Discussion}

The previous analysis of traditional desert cities planning principles demonstrates the responsiveness of the local environment and the exploitation of available resources in it to create cities that provide comfort to the inhabitants and preserve the natural resources. Architecture and traditional urban planning give us examples, how simple principles -which they are based on- it can stay and exist for hundreds of years, and where these principles stand in the face of modern construction methods that have not proved to be more valid than traditional solutions.

Modern cities face many challenges to prove that they are capable of achieving the requirements of sustainable development and environmental protection [15], so the new planning theory should re-explore traditional principles and choose what is appropriate for the local environment and how to develop and blend these principles with modern technologies which make using the principles of traditional architecture easier and more efficient to achieve the principles of sustainable cities.

The most important question that needs to be addressed when talking about the theories of modern city planning in desert cities, is when will be the courage to give the opportunity once again to the integrated urban fabric and support it through flexible building legislation and systems that will play a major role in solving many of the issues facing cities today.

\section{Conclusions}

The study concludes the necessity of following new developmental approaches to develop and formulate sustainable urban communities in the Syrian desert that achieve containment, independence and self-sufficiency without disturbing the ecological system, in addition to integrating the old experiences gained from the traditional desert communities, with contemporary and future standards and needs.

\section{References}

1. W.B. Meyer, The Environmental Advantages of Cities, England (Massachusetts Institute of Technology, 2013)

2. M. Santamouris, Environmental Design of Urban Buildings: An Integrated Approach (Earthscan publishing house, England, 2006)

3. T. Beathley, Planning and Sustainability: The elements of a new paradigm, Journal of Planning Literature publishing house (2016)

4. Ch.W. McPherson, Laboratory hamsters (Academic Press, Orlando, 1987)

5. H. Thomas, The Great Empires of the Ancient World (University of Melbourne, USA, 2009)

6. F.A. Schaeffer Claude, Syria and the Cradle of Civilization: The Findings of Claude F a Schaeffer in Ras Shamra (Trubner \& Co. Publisher, 2003)

7. A. Al-Bunni, K. Al-Assaad, Palmyra Archaeological - Historically - Tourism 4 (2001)

8. Ministry of Public Works, Directorate of Urban Planning, Master Plan of Palmyra (2003) 
9. Y. Elsheshtawy, The Evolving Arab City: Tradition, Modernity and Urban Development (Routledge publishing house, 2008)

10. R. Malloy, J. Brock, A. Floyd, M. Livingston, R.H. Webb, Design with the Desert: Conservation and Sustainable Development (CRC press, 2013)

11. M. DeKay, G.Z. Brown, Sun, Wind, and Light: Architectural Design Strategies (John Wiley\& Sons, 2014)

12. M.A. Mendez, Climate Change from the Streets (University of California, Berkeley, 2015)

13. E. Ng, Designing High-density Cities for Social and Environmental Sustainability (Earthscan publishing house, 2009)

14. H. Lambers, F.S. Chapin III, T.L. Pons, Plant Physiological Ecology (Springer Science \& Business Media, 2008)

15. I. Douglas, I.B. Tauris, Cities: An Environmental History (2013) 